CONSIDERATIONS REGARDING THE DEVELOPMENT OF AN ENVIRONMENTAL CONTROL AND LIFE SUPPORT SYSTEM FOR LUNAR SURFACE APPLICATIONS

\author{
R.M. Bagdigian \\ NASA Marshall Space Flight Center
}

\begin{abstract}
NASA is engaged in early architectural analyses and trade studies aimed at identifying requirements, predicting performance and resource needs, characterizing mission constraints and sensitivities, and guiding technology development planning needed to conduct a successful human exploration campaign of the lunar surface. Conceptual designs and resource estimates for environmental control and life support systems (ECLSS) within pressurized lunar surface habitats and rovers have been considered and compared in order to support these lunar campaign studies. This paper will summarize those concepts and some of the more noteworthy considerations that will likely remain as key drivers in the evolution of the lunar surface ECLSS architecture.
\end{abstract}




\section{Considerations Regarding the Development of an Environmental Control and Life Support System for Lunar Surface Applications}

"LIFE SUPPORT SYSTEMS AS A MEANS OF HUMAN EXPLORATION OF OUTER SPACE"

Moscow, September 24-27, 2008

Robert M. Bagdigian NASA Marshall Space Flight Center Constellation Lunar Surface Systems Project Office 
Considerations Regarding the Development of an Environmental Control and Life Support System for Lunar Outpost Applications

- Lunar Surface Systems Overview

- ECLSS Considerations

* Functions

* Loop Closure

* Commonality

* Mars Extensibility 


\section{Lunar Architecture Studies}

$x^{2}=$

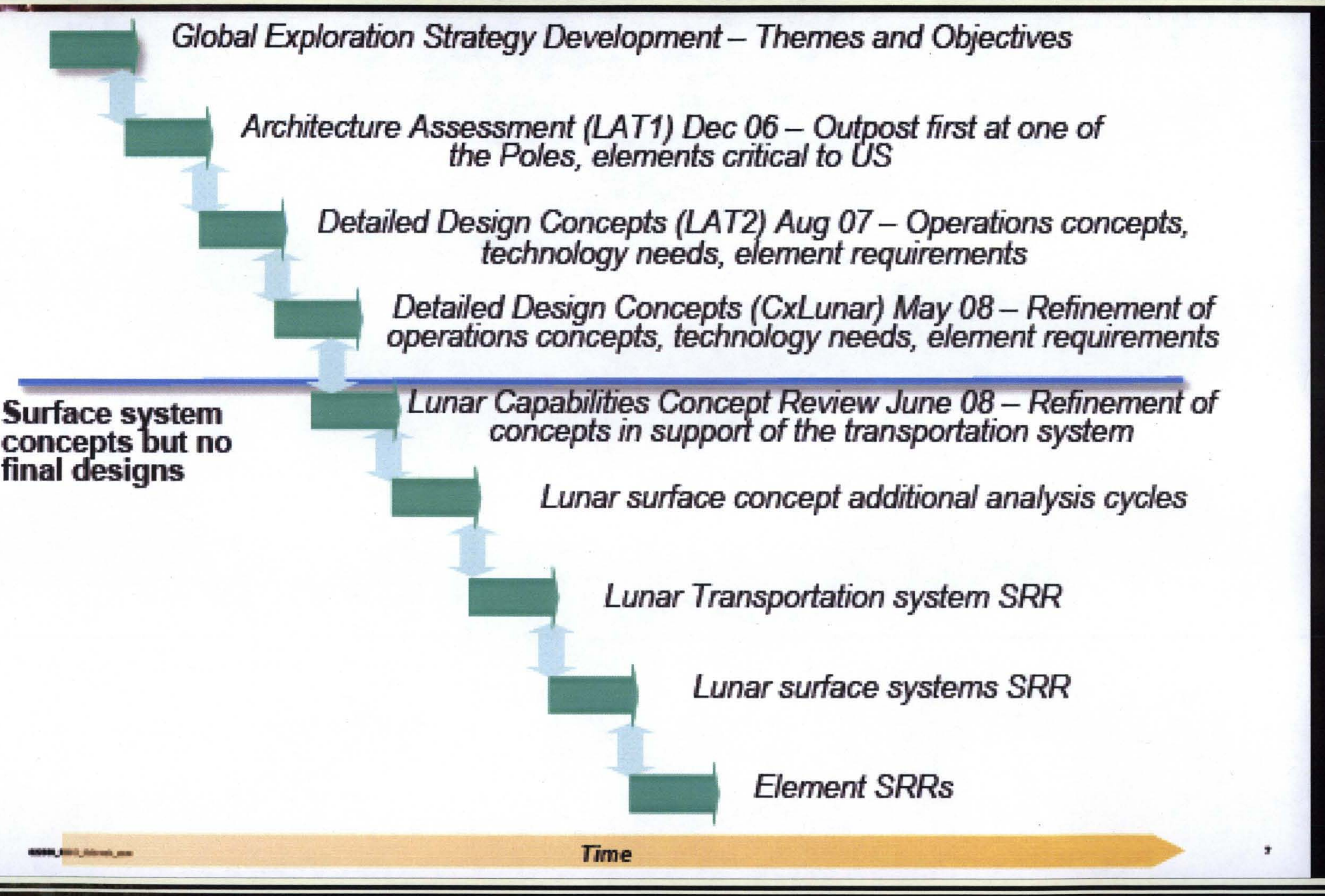




\section{Architecture Desired Attributes}

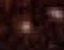

$\checkmark$ Enable lunar sustained presence early

$\checkmark$ Develop infrastructure while actively engaged in science and exploration

$\checkmark$ Ensure architecture supports Objectives

$\checkmark$ Support the establishment of Mars analog

$\checkmark$ Allow the earliest partnership opportunities for commerce and International Partners

$\checkmark$ Continuous and focused public engagement
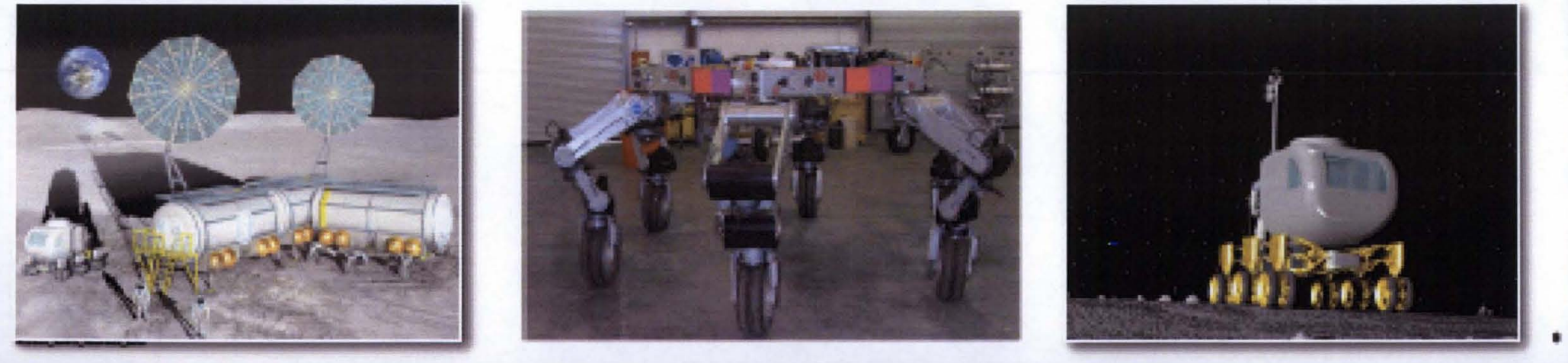


\section{Architecture Guidelines}

- In addition to supporting the basic goals and objectives of the Vision, the Architecture must have the following:

- Programmatic Flexibility - The Architecture must be able to adapt to changes in national priorities and budgets over several election cycles

- Participant Flexibility - The Architecture must be able to adapt to changes in external participation (Commercial or IP) and changes to their priorities

- Exploration Flexibility - The Architecture must be able to adapt to changes in exploration priorities and changes in exploration methods 


\section{Key Elements of an Outpost}

$+=$

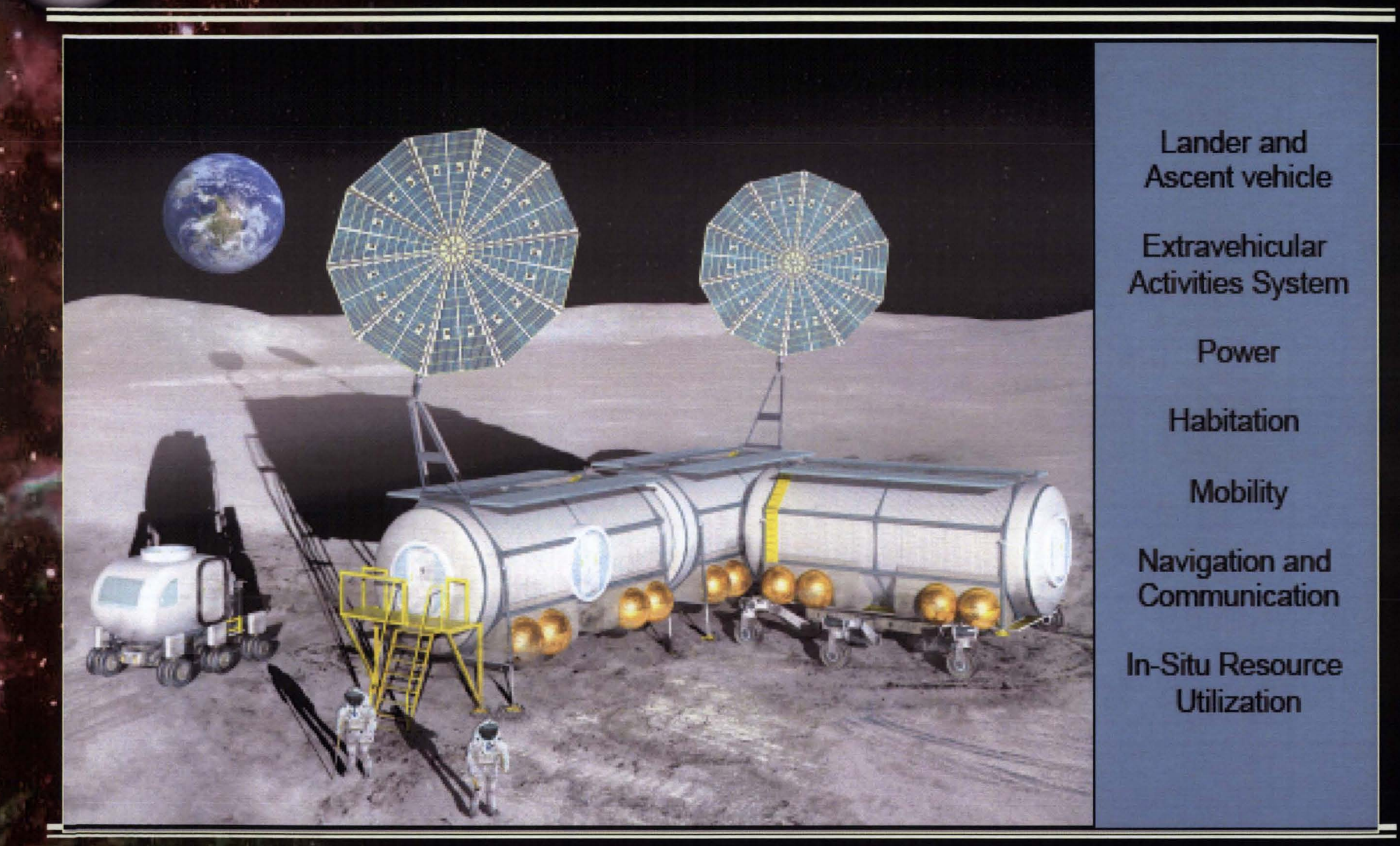




\section{Key Elements of an Outpost}

- Variety of possible end-states

- Variety of possible campaigns

* Early outpost build-up

* Early habitation capability

* Early mobility capability

- Common characteristics

* Pressurized habitat(s)

* Pressurized logistics element(s)

$\therefore$ Pressurized rover(s)

* 4 crew

* 180-day expeditions

* periods of un-crewed dormancy

* frequent EVAs

* resupply capability will not be

* unlimited

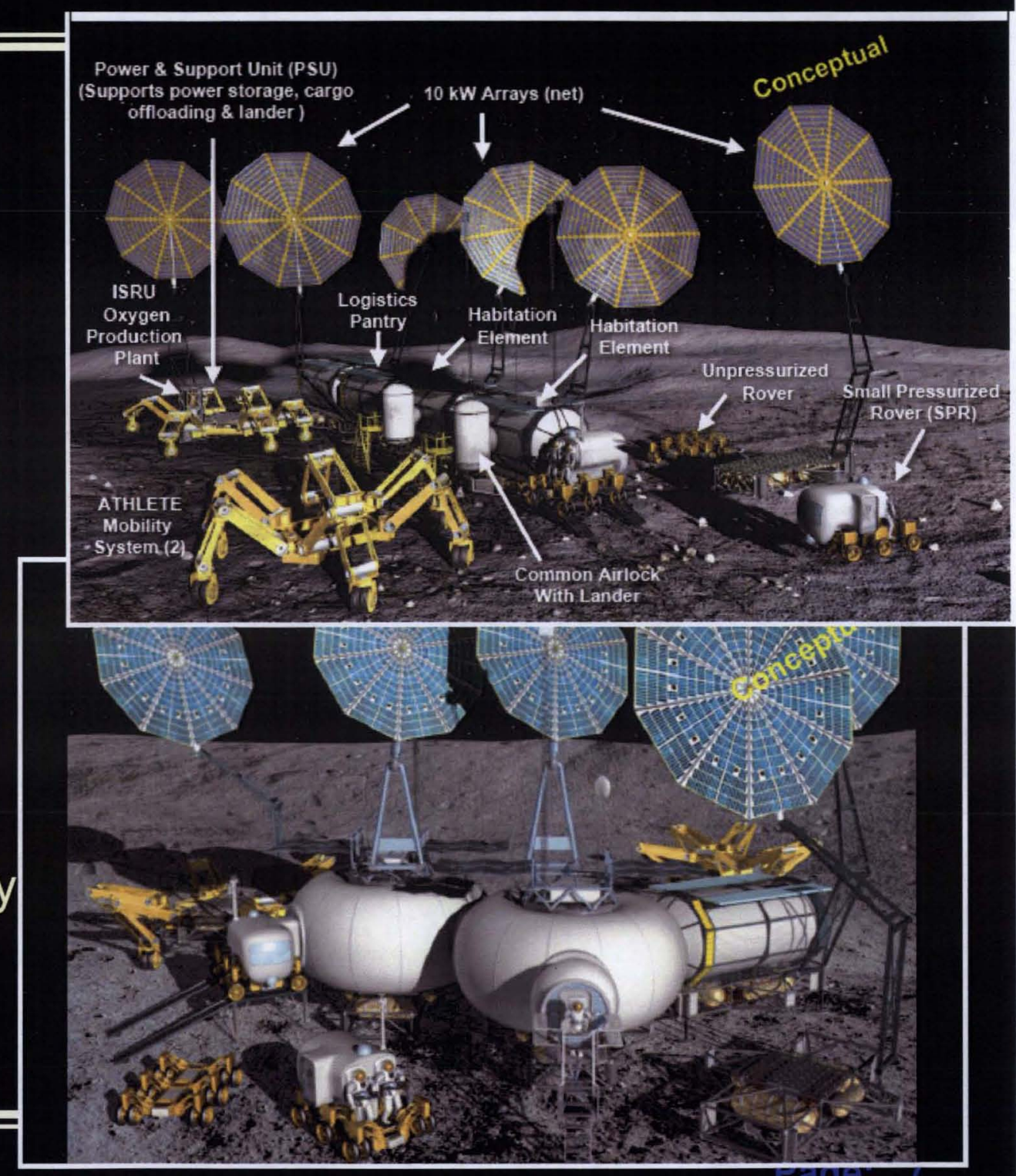




\section{Lunar Surface ECLSS Functions}

$+8$

Pressure Control

O2 Storage \& Supply

N2 Storage \& Supply

Positive Pressure Relief

Intermodule Pressure

Equalization

Cabin Pressure Monitoring

.

Fire Detection \& Suppression

- Fire Detection (function potentially provided or supported by atmosphere monitoring equipment)

- Fire Suppression

4

\section{Emergency Response}

O2 Masks

- Toxic Masks
Air Revitalization

- CO2 Removal

- CO2 Reduction

- O2 Generation

- Temperature \& Humidity Control

- Trace Contaminant Control

* regenerative

* non-regenerative (for module ingress)

- Ventilation

* intra-module

* inter-module

- Airborne Particulate Control and Monitoring

- Atmosphere Composition Monitoring

$$
\begin{aligned}
& \text { * ppO2 } \\
& \text { - pp CO2 } \\
& \text { * } \text { pp H2O (v) } \\
& \text { - Trace Contaminants }
\end{aligned}
$$

Water Recovery \& Mgmt

- H2O Recovery

* Humidity Condensate

* Waste Hygiene

* Urine

- Brine Recovery

- Water Storage \& Distribution

- Water Quality Monitoring

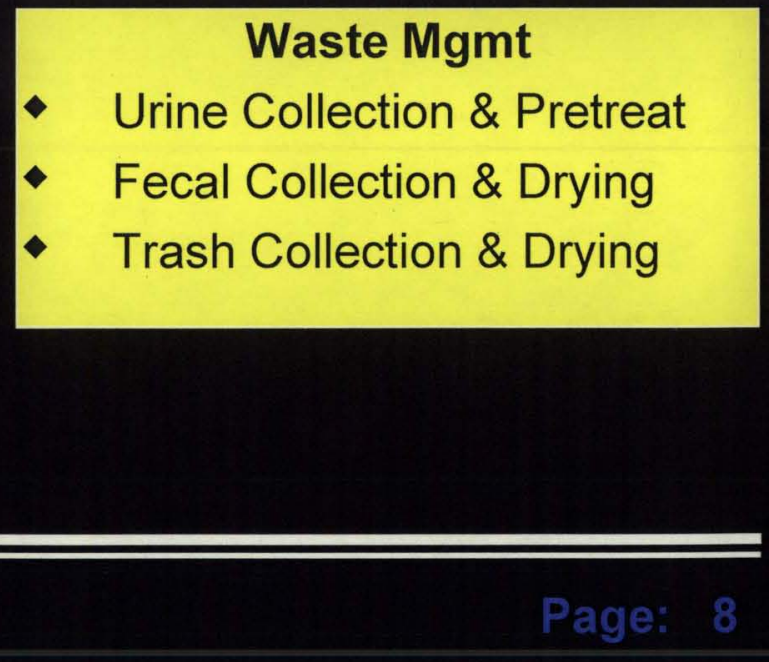




\section{Typical Distribution of ECLSS Functions}

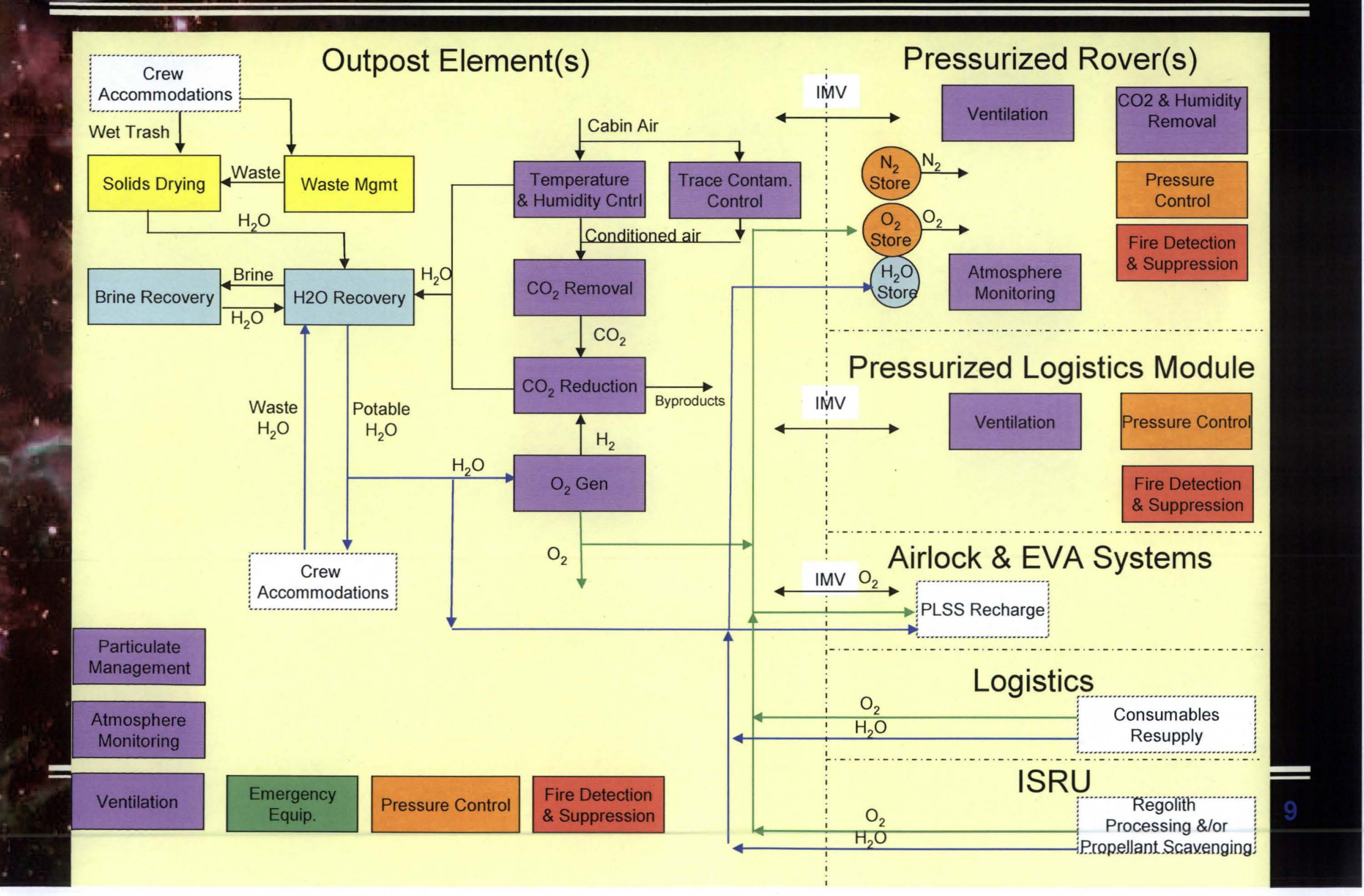


Notional Daily 4-Person Metabolic ..

\section{Mass Balance}

Ag

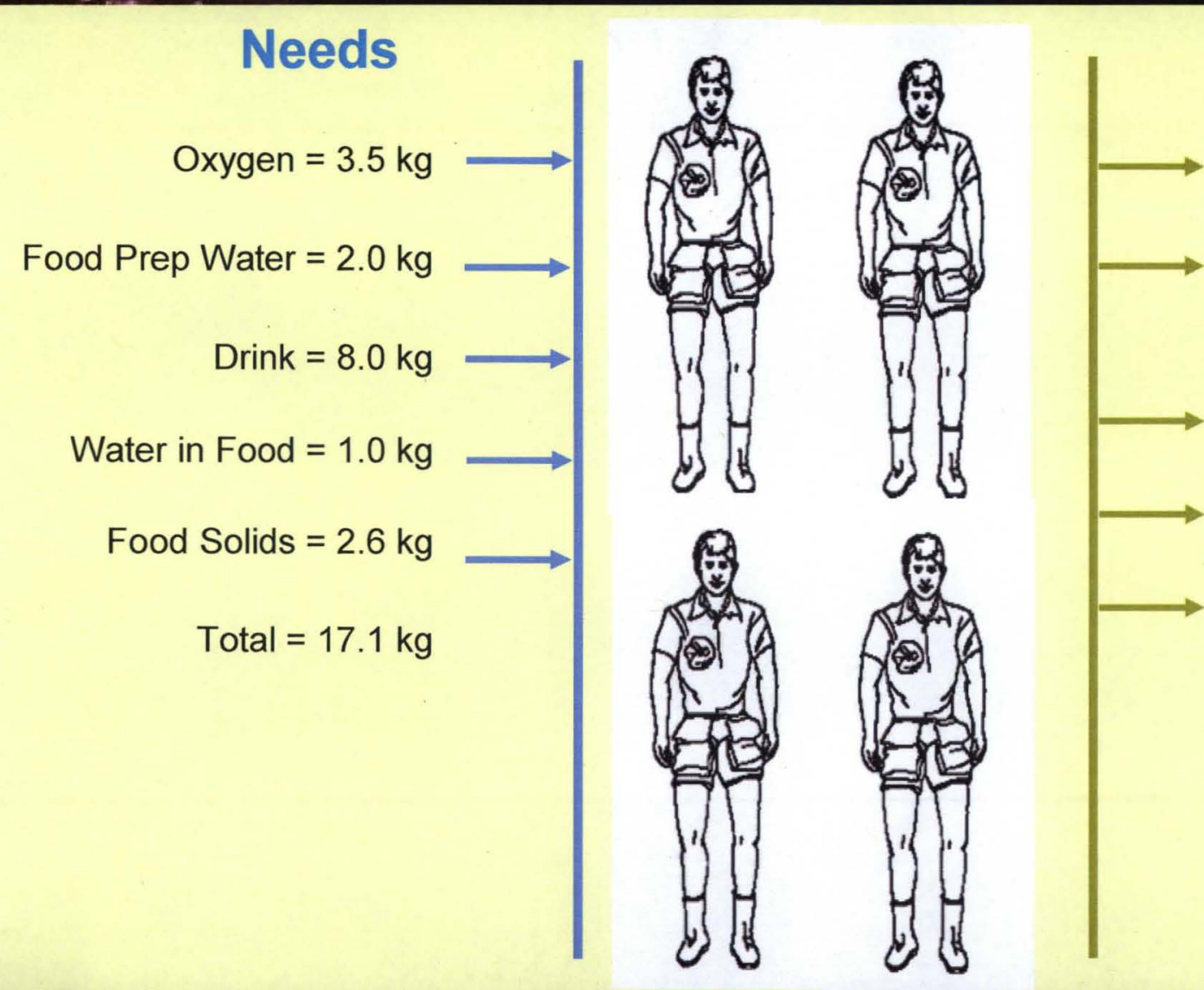

Wastes

Carbon Dioxide $=4.4 \mathrm{~kg}$

Respiration \& Perspiration

Water $=6.6 \mathrm{~kg}$

Urine $=5.6 \mathrm{~kg}$

Fecal Water $=0.4 \mathrm{~kg}$

Fecal, Urine, \& Sweat Solids $=0.1 \mathrm{~kg}$

Total $=17.1 \mathrm{~kg}$ 


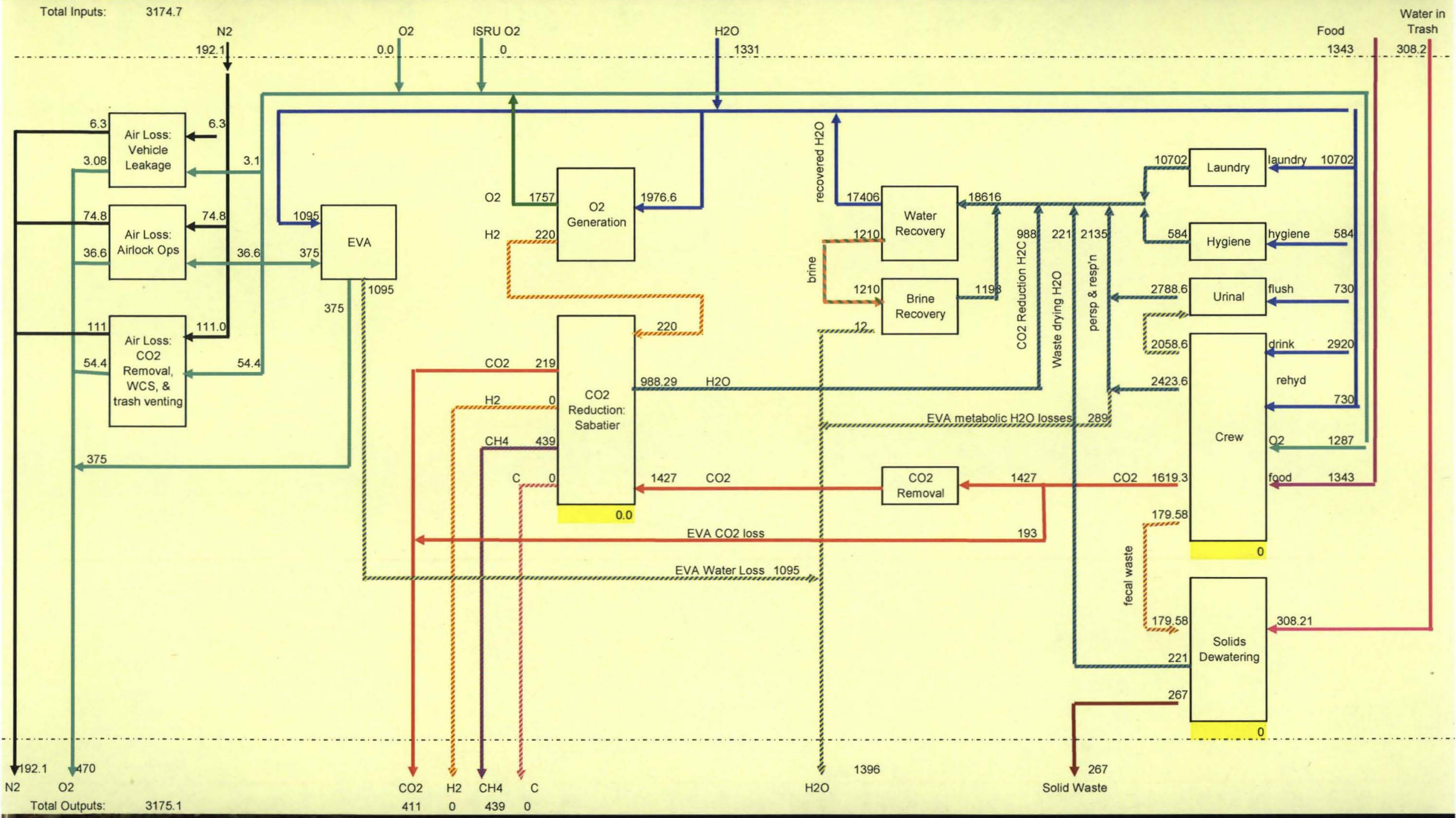




\section{Balancing Loop Closure vs. Risk}

- Variety of candidate technology options \& combinations exist for O2 \& $\mathrm{H} 2 \mathrm{O}$ recovery

- Benefit (reduced re-supply) must be considered in light of risks that would work against achieving the benefit

- programmatic risks

- operational risks

- Objective and complete means of assessing risks is needed

- more difficult for low TRL

- candidates with little supporting data

$\therefore \quad$ uncertainties must be applied to - benefit \& risk estimates
Notional Re-Supply vs. Risk Comparison for a Family of Loop Closure Technology Options

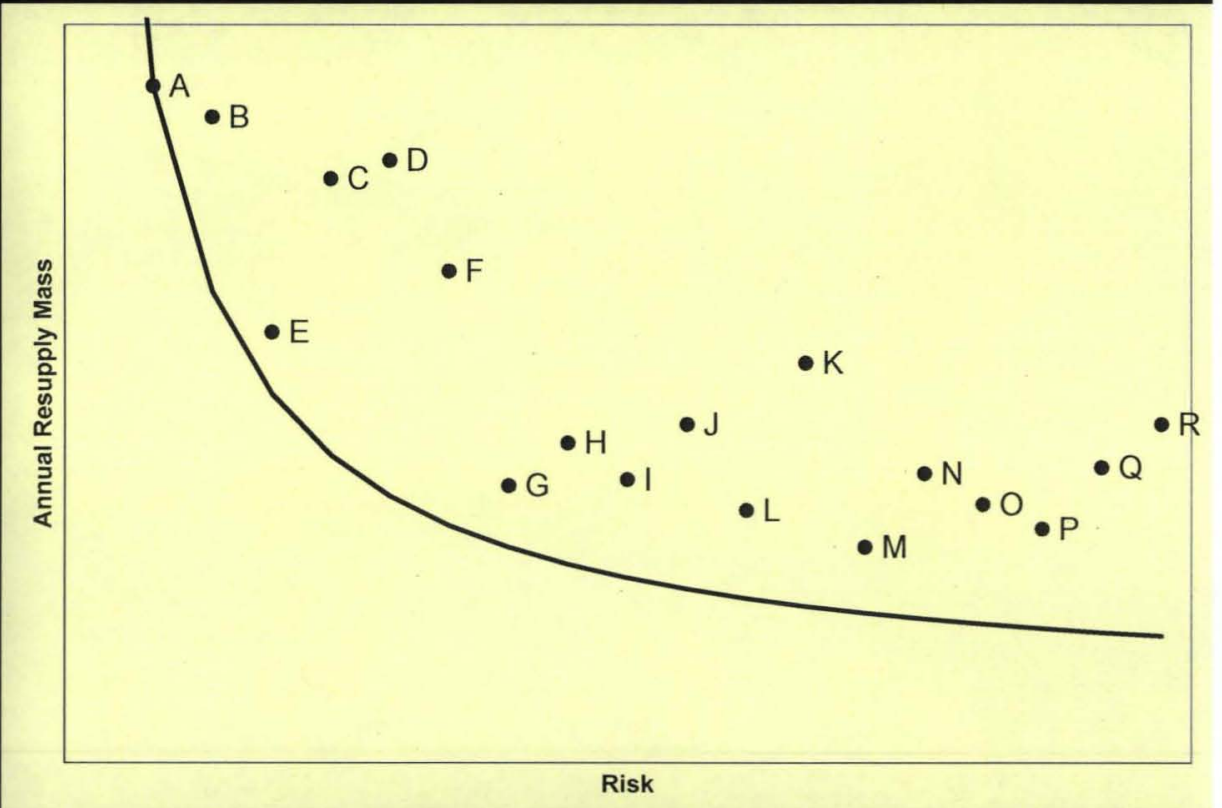




\section{Degree of New Design for a Notional Outpost}

B.

$\square 1$ "Reflight of Existing Spacecraft, Technology Readiness Level-9: Actual system "flight proven" through successful mission operations"

$\square 2$ "Minor Modifications Not Requiring Re-Qualification, Technology Readiness Level-9"

$\square 3$ "Minor Modifications Requiring Re-Qualification, Technology Readiness Level-9"

"Moderate Modifications, Technology Readiness Level-9: Actual system "flight proven" through successful mission 4 operations"

$\square \quad 5$ "Moderate Modifications, Technology Readiness Level-8: Actual system completed and "flight qualified" through test 5 and demonstration (ground or space)"

$\square 6$ "Significant Modifications, Technology Readiness Level-7: System prototype demonstration in a space environment"

"Significant Modifications, Technology Readiness Level-6: System/subsystem model or prototype demonstration in a 7 relevant environment (ground or space)"

$\square$ "Based on a Previous Design, Technology Readiness Level-5: Component and/or breadboard validation in relevant 8 environment"

$\square$ "Similar to a Previous Design, Technology Readiness Level-4: Component and/or breadboard validation in laboratory 9 environment"

10 "New Design, TRL-3 thru Technology Readiness Level-1: Analytical and experimental critical function and/or characteristic proof-of-concept"

Total Outpost

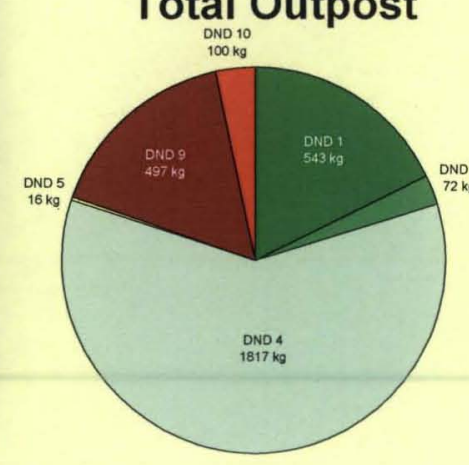

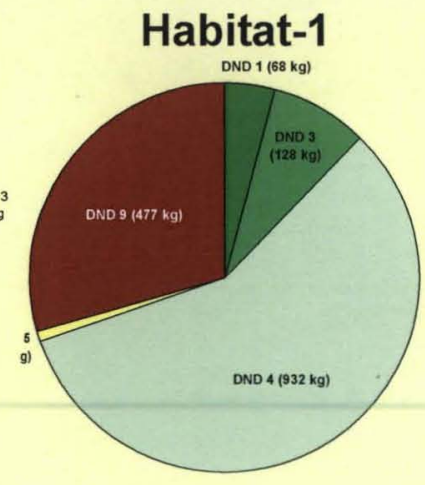

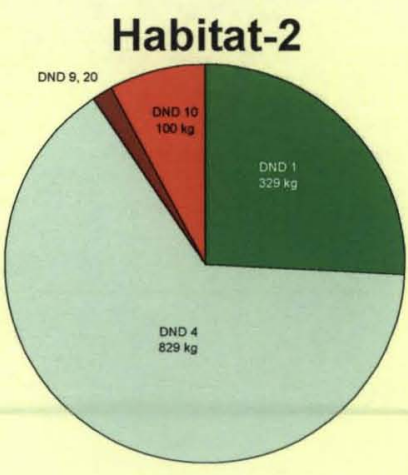

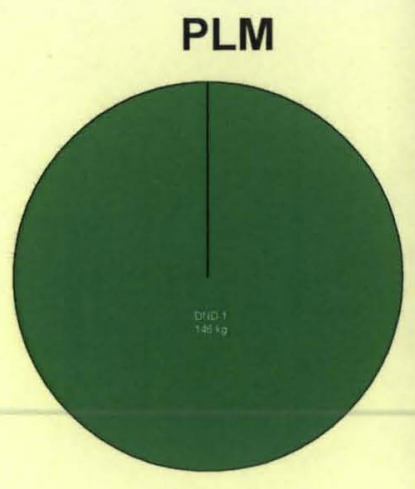




\section{Extensibility to Mars}

- Maŕs mission characteristics

* months-long transits to \& from

* surface stays on the order to 500 days

* quick emergency return unlikely

* planetary protection policies

- How the lunar outpost ECLSS might help

* establish \& validate long-term reliability in an operational environment

* demonstrate \& gain experience

- with "zero-release" technologies \& operations that

- minimize environmental impact

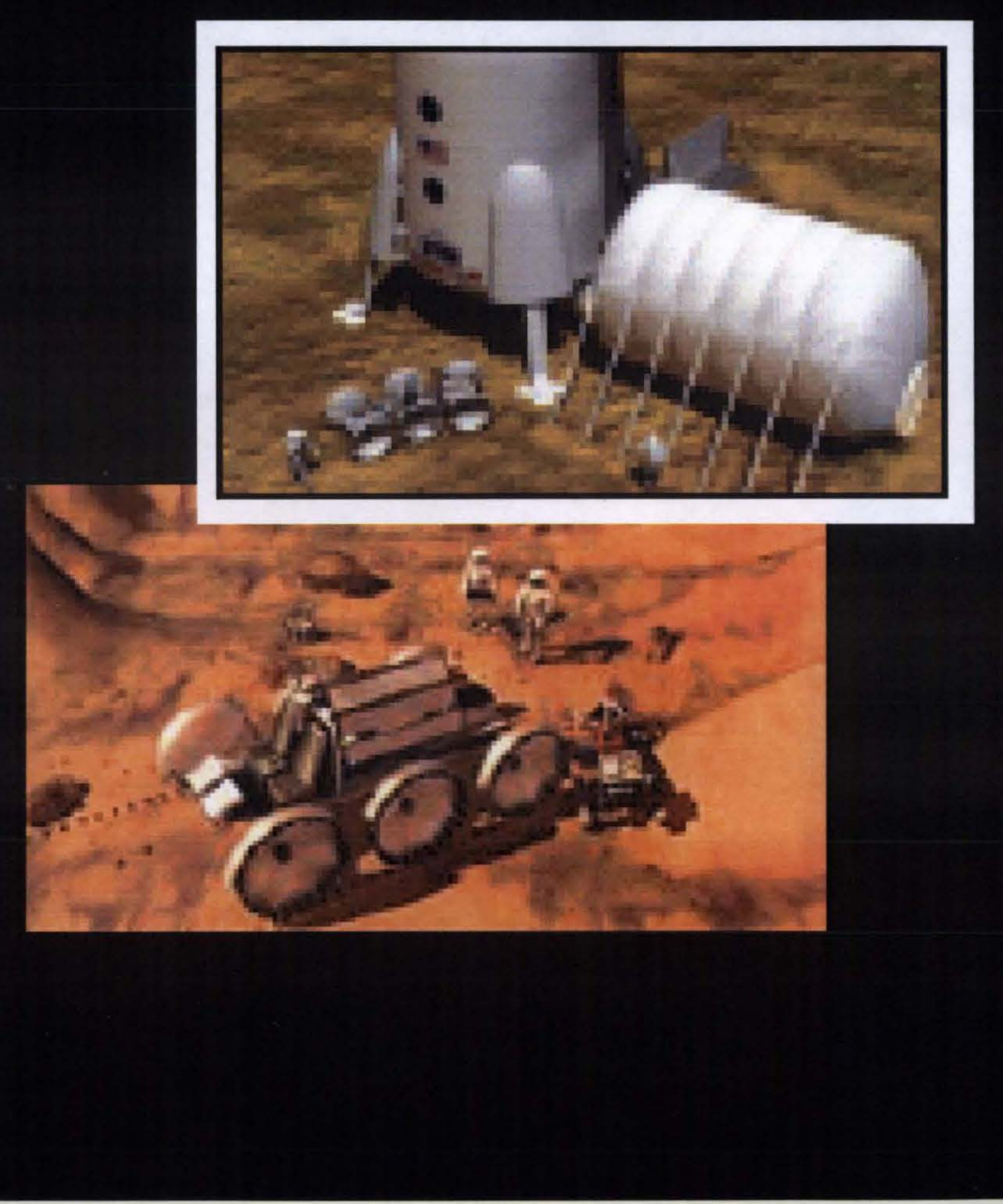




\section{Lunar Surface Systems: Next Steps}

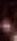

- Continue to refine lunar architecture concepts

* Target surface systems concept review in 2010 or 2011 timeframe

- Continue to expand architecture participation with international and commercial entities

- Focus on identifying innovative approaches, complementary concepts, and necessary technologies, not on detailed designs of specific elements

- Explore a wide variety of scenarios that:

* Consider different ways to build up the Lunar capability over time

- * Assess multiple viewpoints on figures of merit for various lunar surface system capabilities 